\title{
Snow on the Ross Ice Shelf: comparison of reanalyses and observations from automatic weather stations
}

\author{
L. Cohen ${ }^{1}$ and S. Dean ${ }^{2}$ \\ ${ }^{1}$ Antarctic Research Centre, Victoria University, Wellington, New Zealand \\ ${ }^{2}$ National Institute of Water and Atmospheric Research, Wellington, New Zealand \\ Correspondence to: L. Cohen (lana.cohen@vuw.ac.nz) \\ Received: 1 March 2013 - Published in The Cryosphere Discuss.: 25 March 2013 \\ Revised: 8 July 2013 - Accepted: 5 August 2013 - Published: 16 September 2013
}

\begin{abstract}
Snow accumulation measurements from automatic weather stations (AWS) around the Ross Ice Shelf (RIS), Antarctica, are used to provide a new set of groundbased observations which are compared to precipitation from the ECMWF ERA-Interim and NCEP/NCAR Reanalysis-2 datasets. The high temporal resolution of the AWS snow accumulation measurements allow for an event-based comparison of reanalyses precipitation to the in situ observations. Snow accumulation records from nine AWS provide multiple years of accumulation data between 2008 and 2012 over a relatively large, homogeneous region of Antarctica, and also provide the basis for a statistical evaluation of accumulation and precipitation events. The complex effects of wind on snow accumulation (which can both limit and enhance accumulation) complicate the use of the accumulation measurements, but this analysis shows that they can provide a valuable source of ground-based observations for comparisons to modelled precipitation on synoptic timescales. The analysis shows that ERA-Interim reproduces more precipitation events than NCEP-2, and these events correspond to an average $8.2 \%$ more precipitation. Significant correlations between reanalyses and AWS event sizes are seen at several stations and show that ERA-Interim consistently produces larger precipitation events than NCEP-2.
\end{abstract}

\section{Introduction}

Knowledge of the spatial and temporal variability of precipitation and snow accumulation in Antarctica is essential for further understanding of Antarctic mass balance, ice core interpretation, and atmospheric circulation changes. Because of the sparseness of in situ and satellite measurements in Antarctica, atmospheric reanalyses products are a key tool for studying precipitation in Antarctica (e.g. Monaghan et al., 2006; Krinner et al., 2007; Marshall, 2009; Bromwich et al., 2012). The European Centre for Medium-Range Weather Forecasts (ECMWF) ERA-Interim and National Centers for Environmental Predication/National Center for Atmospheric Research (NCEP/NCAR) Reanalysis-2 datasets are the most easily accessible and provide data over the longest time period (1979-present for the polar regions), and they are therefore widely used in climatological and meteorological studies of Antarctica. Understanding how well precipitation is represented by these reanalyses products (and other numerical weather prediction (NWP) models) is difficult to ascertain because of the difficulty in making precipitation measurements and the sparseness of these measurements in the high latitudes.

Previous studies have focused on annual and longer timescales, and primarily use glaciological observations (e.g. Cullather et al., 1998; Bromwich et al., 2004, 2007, 2011). These studies provide valuable information on trends and large-scale variability of precipitation, and show that there are significant differences in precipitation representation between various reanalyses datasets. Most recently, Bromwich et al. (2011) showed that the ERA-Interim dataset represents the spatial variability and recent trends in precipitation over most of Antarctica better than the NCEP-2 dataset. However, this assessment is based on annually averaged precipitation from satellite and glaciological observations and does not give insight into how well reanalyses represent precipitation on much shorter timescales. In addition, ongoing challenges with use of satellite observations 
for verification of NWP modelled precipitation (e.g. Lu et al., 2010) indicate that there is still a considerable need for in situ precipitation observations.

Understanding how well reanalyses precipitation is represented on synoptic scales is of interest primarily for ice core interpretation and atmospheric circulation change studies (e.g. Simmonds et al., 2003; Helsen et al., 2007; Thomas and Bracegirdle, 2009; Sinclair et al., 2010; Fogt et al., 2012). Synoptic-scale systems drive much of the temporal and spatial variability of precipitation in Antarctica, and understanding how that variability affects climate proxies in ice cores is very important (Noone and Simmonds, 2002). The Ross and Amundsen seas in particular are regions of significant synoptic-scale cyclone activity in the Southern Ocean which are the source of most of the precipitation on the Ross Ice Shelf and West Antarctic Ice Sheet (King and Turner, 1997; Simmonds et al., 2003). The synoptic variability of these regions are of interest and the source of ongoing research as they are known to be influenced by large-scale atmospheric circulation changes such as the Southern Annular Mode and El Niño-Southern Oscillation (Cullather et al., 1996; Fogt and Bromwich, 2006; Fogt et al., 2012; Cohen et al., 2013).

Snow accumulation measurements from the University of Wisconsin Antarctic Meteorological Research Center (UW-AMRC) network of unmanned automatic weather stations (AWS) provide a source of in situ observations which may be used to assess reanalyses precipitation on synoptic scales. This study compares accumulation measurements from the Ross Ice Shelf, Antarctica, to individual precipitation events from the ECMWF ERA-Interim and NCEP/NCAR Reanalysis-2 datasets. The stations provide measurements of snow accumulation via changes in snow height as well as the standard suite of meteorological parameters (temperature, pressure, relative humidity, and wind speed and direction) (Lazzara et al., 2012). Snow height changes are measured with acoustic depth gauge (ADG) instruments which measure the amount of snow accumulation and exact timing of accumulation events. ADGs have been widely used in Antarctic studies to characterize precipitation and surface mass balance on sub-annual timescales (e.g. Braaten, 1997, 2000; Qin et al., 2004; Eisen et al., 2008; Reijmer and Van den Broeke, 2003; Thiery et al., 2012) and in climate proxy studies to investigate the synoptic origins of individual accumulation events (e.g. Reijmer et al., 2002; Helsen et al., 2007).

As snow accumulation records are a proxy for precipitation, using them to compare to precipitation is not straightforward. The ADG measurements on the Ross Ice Shelf provide a new dataset of high temporal resolution, ground-based accumulation observations which may provide an important source of measurements to assess modelled precipitation on synoptic timescales.

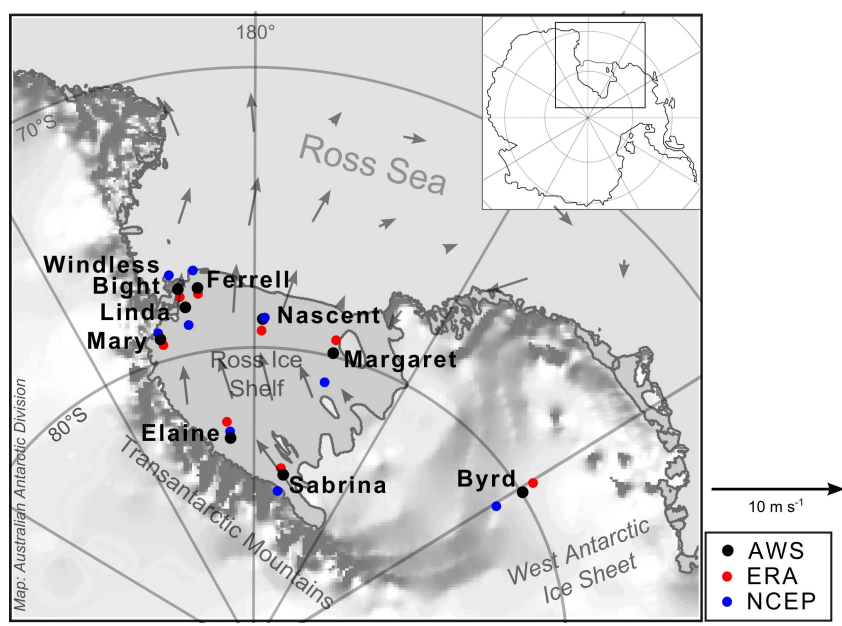

Fig. 1. Locations of the automatic weather stations (AWS) used in this study and corresponding grid point locations for ERA-Interim (red) and NCEP-2 (blue) reanalyses. Wind vectors show the climatological surface wind regime $(850 \mathrm{hPa})$ over the RIS and Ross Sea (from ERA-Interim monthly data averaged over 2008-2012).

\section{Site description and snow accumulation data}

Figure 1 shows the locations of the nine UW-AMRC AWS snow height measurements used in this study and the nearest ERA-Interim and NCEP-2 grid points. The eight stations on the Ross Ice Shelf (RIS) provide a relatively dense network of stations in a geographically constrained area. We also use data from a station located on the West Antarctic Ice Sheet (WAIS) because of its proximity to the RIS and the significance of the WAIS for mass balance and ice core interpretation. The snow height change measurements are available for varying time periods between January 2008 and August 2012. Though there are some measurements prior to 2008 , continuous, year-round snow accumulation measurements have only been available since 2008. All of the stations except for Linda and Byrd have over two years of continuous accumulation measurements, with Windless Bight having the longest record of $4.5 \mathrm{yr}$. Each station's length of record, location, and distances to nearest reanalyses grid points are summarized in Table 1.

Knowledge of the surface wind regime of the RIS is important to help interpret the ADG accumulation measurements, because wind redistribution can be a significant component of snow accumulation (Bromwich, 1988). The RIS is a topographically flat ice shelf bordered to the south and west by the Transantarctic Mountains (TAM), which rise to over $4000 \mathrm{~m}$, and to the east by the Siple Coast, which rises gradually to the WAIS at $\sim 2000 \mathrm{~m}$ elevation. Katabatic winds, which flow from the ice sheets through the outlet valleys in the TAM and Siple Coast, and barrier winds, which are the result of cold, stable air forced along the TAM, are common features of the surface wind field of the 
Table 1. AWS locations, elevations, dates and lengths of ADG records, and distances to nearest ERA-Interim and NCEP-2 grid points.

\begin{tabular}{lccccc}
\hline Station & Location & $\begin{array}{c}\text { Elev. } \\
(\mathrm{m})\end{array}$ & $\begin{array}{c}\text { Dates of ADG data \& } \\
\text { Length of Record (yr) }\end{array}$ & $\begin{array}{c}\text { Distance to } \\
\text { ERA/NCEP }(\mathrm{km})\end{array}$ \\
\hline Byrd & $80.007^{\circ} \mathrm{S}, 119.404^{\circ} \mathrm{W}$ & 1530 & Nov 2011-Aug 2012 & 0.8 & $58 / 105$ \\
Sabrina & $84.247^{\circ} \mathrm{S}, 170.068^{\circ} \mathrm{W}$ & 88 & Jan 2010-Aug 2012 & 3.5 & $29 / 57$ \\
Elaine & $83.094^{\circ} \mathrm{S}, 174.285^{\circ} \mathrm{E}$ & 58 & Jan 2010-Aug 2012 & 2.6 & $66 / 27$ \\
Margaret & $80.000^{\circ} \mathrm{S}, 165.000^{\circ} \mathrm{W}$ & 67 & Nov 2008-Aug 2012 & 3.8 & $56 / 105$ \\
Nascent & $78.129^{\circ} \mathrm{S}, 178.498^{\circ} \mathrm{W}$ & 30 & Jan 2009-Apr 2011 & 2.3 & $44 / 10$ \\
Mary & $79.305^{\circ} \mathrm{S}, 162.985^{\circ} \mathrm{E}$ & 58 & Jan 2008-Dec 2011 & 3.8 & $24 / 29$ \\
Linda & $78.426^{\circ} \mathrm{S}, 168.418^{\circ} \mathrm{E}$ & 42 & Nov 2011-Aug 2012 & 0.8 & $50 / 68$ \\
Ferrell & $77.833^{\circ} \mathrm{S}, 170.819^{\circ} \mathrm{E}$ & 45 & Jan 2009-Dec 2010 & 2.0 & $19 / 77$ \\
Windless Bight & $77.725^{\circ} \mathrm{S}, 167.687^{\circ} \mathrm{E}$ & 40 & Jan 2008-Aug 2012 & 4.6 & $31 / 68$ \\
\hline
\end{tabular}

RIS (King and Turner, 1997; Parish et al., 2006). The surface wind regime is also influenced by synoptic-scale and mesoscale cyclones, which enhance and provide forcing for katabatic and barrier wind regimes (King and Turner, 1997).

Figure 1 shows the climatological near-surface $(850 \mathrm{hPa})$ winds on the Ross Ice Shelf (from the ERA-Interim reanalysis data), which illustrates the varying wind conditions experienced at different stations. Most of the AWS are located in katabatic outflow paths (Mary, Linda, Elaine, Ferrell, Nascent, and Byrd) and barrier wind regimes (Sabrina), and as a result these sites experience strong winds more often than the other sites (Braaten, 1997; Parish et al., 2006; Knuth et al., 2010; Nigro et al., 2011). We expect the snow accumulation at these sites may be more affected by wind redistribution than other sites such as Margaret, which is located on the eastern side of the RIS near Roosevelt Island. The Windless Bight site, located near Ross Island on the northwestern edge of the RIS, is also less affected by strong wind regimes, but is known to experience high accumulation compared to other sites due to its location on the windward side of Ross Island (Monaghan et al., 2005).

Wind redistribution of snow is a significant and ongoing challenge for studying precipitation events in Antarctica because the process is complex and dependent on many additional factors such as snow age, air temperature, snow moisture, local topography (down to metre-scale sastrugi), and snow grain size (Li and Pomeroy, 1997). Increases in measured snow accumulation at a site can occur due to either precipitation or blowing snow, or both, as precipitation often occurs in conjunction with high wind speeds. Increases in accumulation due to clear-sky precipitation and hoar frost are not considered significant for this region (Bromwich, 1988). Decreases in accumulation due to ablation, compaction, and sublimation are significant contributors to net accumulation but can be largely ignored in this study as the eventbased analysis only considers positive changes in accumulation. The densification of the snowpack that occurs on the timescale of an event $(<100 \mathrm{~h})$ is less than $1 \mathrm{~mm}$ (Arthern et al., 2010), and can thus be ignored for this study. However, the densification of snow deposited during an event due to wind can significantly increase surface snow densities (Pomeroy and Brun, 2001), and this is considered further in the analysis.

As wind is the primary factor affecting the magnitude of measured accumulation (both positively and negatively), previous studies can help provide some estimate of the frequency of high winds occurring during accumulation events on the RIS and their effects on measured accumulation (Braaten, 1997, 2000; Knuth et al., 2010). Based on wind speed measurements for several stations on the RIS, Knuth et al. (2010) showed that most (72\%) measured large accumulation events ( $>1 \mathrm{~cm}$ per $30 \mathrm{~min}$ ) were associated with blowing or drifting snow which may or may not have been concurrent with precipitation. In another study on the RIS, Braaten (1997) showed that while most ADG-measured accumulation events were associated with human-observed precipitation events (using a much smaller event size threshold of $1.3 \mathrm{~mm}$ ), less than half of the observed events ( $38 \%$ ) resulted in measurable accumulation by the instrument.

Here we describe a methodology for identifying accumulation events within the ADG records, which allows for these measurements to be used to compare with reanalyses precipitation. By utilizing long records from a large number of stations we can construct a statistical comparison, which still acknowledges the imperfections in the observations. This approach allows for a straightforward validation of the timing and duration of individual events in the reanalyses datasets. Comparison of the sizes of these events requires conversion of a snow height change to a mass (water equivalency) and ideally requires a measurement of snow density at each site and event. Since this information is not available, we consider a range of snow densities that include the full range of freshly deposited snow (70-120 $\mathrm{kg} \mathrm{m}^{-3}$ for temperatures $<+1{ }^{\circ} \mathrm{C}$ ) and wind-redistributed snow (from $250 \mathrm{~kg} \mathrm{~m}^{-3}$ and up) (Pomeroy and Brun, 2001). We use an average surface (the top 1-4 m) snowpack density of $350 \mathrm{~kg} \mathrm{~m}^{-3}$ to compare the multi-year accumulation records (Kojima, 1964). 


\section{Data processing}

\subsection{ADG data}

Snow accumulation is measured with a Campbell Scientific SR50 acoustic depth gauge (ADG), which determines the distance to the snow surface using reflected sonic pulses. The SR50 has a resolution of $0.0001 \mathrm{~m}$ and accuracy of $0.01 \mathrm{~m}$ or $0.04 \%$ of sensor height (whichever is larger). The instrument measures the distance to snow surface from the speed of reflected sonic pulses, and spurious measurements can occur due to drifting and blowing snow reflecting the acoustic signal, high winds $\left(>18 \mathrm{~m} \mathrm{~s}^{-1}\right)$ (Brazenec and Doesken, 2005), low temperatures $\left(<-35\right.$ to $\left.-40^{\circ} \mathrm{C}\right)$ (Fountain et al., 2010), and rime or ice on the sensor. The temperature-corrected ADG data were retrieved from the University of Wisconsin AMRC ftp site (ftp://amrc.ssec.wisc.edu). Further information and specifications on the AWS instrumentation and network is described in Lazzara et al. (2012) and on the University of Wisconsin AMRC site (http://amrc.ssec.wisc.edu).

Snow accumulation records for each station were produced by removing null measurements and measurements that do not represent physical accumulation (i.e. spurious data points outside of the initial and final accumulation values). The ADG data were recorded at a 10 min sampling rate except for Nascent, which is at 20 min resolution. The ADG sensor heights are periodically adjusted to keep the sensors $\sim 1$ to $2 \mathrm{~m}$ above the snow surface, and these height adjustments were applied based on the maintenance logs.

The datasets all contain some high-frequency noise which was minimized using the same methodology as Fountain et al. (2010), which removes data outside of one standard deviation of a running daily value. Since snow accumulation due to precipitation is stepped and episodic, the removal of data points outside of the daily standard deviation removes some of the high-frequency noise while retaining the amplitude of an accumulation event, though the timing can be shifted by up to one day. The ADG data were then averaged to a 3-hourly resolution in order to compare with the reanalyses datasets.

The ADG records are continuous with no large gaps except for Mary and Windless Bight, which have gaps during the winter months of 2011 (June-October). Removal of spurious data, high-frequency noise, and gaps in the raw data account for between 1.5 and $6.8 \%$ of the data in all stations except for Mary and Windless Bight, which are missing $17.1 \%$ and $22.5 \%$ of their data respectively.

\subsection{Reanalyses data}

Reanalyses assimilate in situ meteorological data and satellite data into a global circulation model to produce comprehensive global datasets of meteorological parameters at regular vertical and horizontal resolutions throughout the atmosphere. This study investigates the precipitation products from the NCEP-2 (NCEP) and the ERA-Interim (ERA) reanalyses datasets (Kalnay et al., 1996; Dee et al., 2011). The NCEP reanalysis provides parameters at $2.5^{\circ}$ latitude/longitude resolution through 30 June 2012; ERA provides parameters at $1.5^{\circ}$ latitude/longitude resolution through 31 August 2012 (though the underlying models for both are run at higher resolution).

Though both reanalyses datasets assimilate meteorological observations from the AWS network, the snow accumulation data are not used. Precipitation products from both reanalyses rely entirely on the model's representation of the hydrological processes as they are not directly constrained by observational data (Dee et al., 2011). The ERA forecast model runs at both higher spatial and temporal resolution than the NCEP model (3-hourly intervals versus 6-hourly intervals, and $\sim 80 \mathrm{~km}$ versus $\sim 210 \mathrm{~km}$ horizontal resolution). Thus, we expect the ERA precipitation model to perform better in regards to reproducing precipitation on smaller spatial and temporal scales. In addition, ERA reanalysis also incorporates more satellite observations (including GPS radio occultation measurements) and uses a more sophisticated variational assimilation system (4-D-Var versus 3-D-Var). Differences between ERA and other reanalyses precipitation products since 2006 have been attributed to the assimilation of the new satellite observations (Bromwich et al., 2011), and the more sophisticated variational assimilation system in ERA has also been shown to result in improved moisture analysis (Andersson et al., 2007; Simmons et al., 2010).

The NCEP precipitation is given as an instantaneous precipitation rate, $\mathrm{kg} \mathrm{m}^{-2} \mathrm{~s}^{-1}$ water equivalent (w.e.), averaged over each $6 \mathrm{~h}$ forecast period, which we convert to $\mathrm{m}$ w.e. For ERA, total precipitation is derived from the 3-hourly forecast fields and given in $\mathrm{m}$ w.e. Precipitation data from the reanalyses grid points nearest to each AWS location are used for the analysis. Distances from the stations are listed in Table 1 and shown in Fig. 1.

Most of the grid points are relatively close to their respective AWS, and all are less than $\sim 100 \mathrm{~km}$ from the AWS. Stations located in the region that has the highest topographic gradient (near the TAM) are closest to their respective grid points, which helps minimize differences due to orographically induced precipitation. Smaller topographic features such as Ross Island and Roosevelt Island are not resolved topographically in either of the reanalyses, and thus, localized precipitation due to these features is not expected to be reproduced. For large-scale, synoptically driven precipitation events, the distances between grid points and AWS will not affect the timing or amount of precipitation considerably.

\subsection{Determination of coincident events}

Individual accumulation events are identified from the daily accumulation values for each dataset. As with Fountain et al. (2010), we found that the ADG measurements were able to resolve relative changes in snow height as small as $5 \mathrm{~mm}$ 

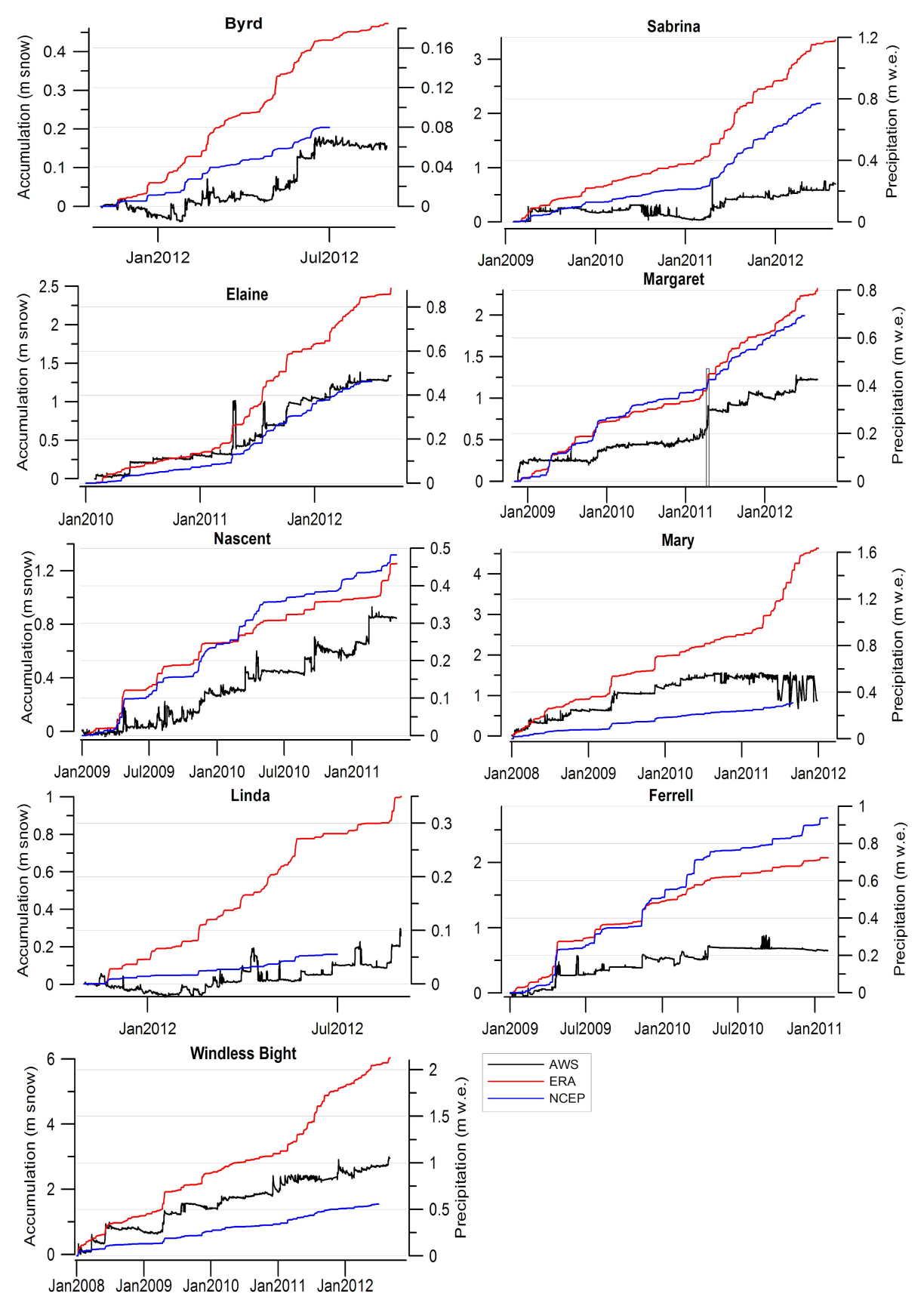

Fig. 2. Total accumulation and precipitation over time for each station (note different time periods). ADG accumulation is in $m$ snow (lefthand axes) and ERA and NCEP reanalyses is in m w.e. (right-hand axes), with axes offset by $35 \%$ (approximate density of surface snow on RIS). A close up of the time period outlined by the grey box in the Margaret plot is shown in Fig. 4.

snow day ${ }^{-1}$, and set that as the event size cutoff for the ADG datasets. For the reanalyses data cutoff value, we use $0.5 \mathrm{~mm}$ w.e. day ${ }^{-1}$, which is equivalent to the ADG cutoff using a mid-range fresh snow density of $100 \mathrm{~kg} \mathrm{~m}^{-3}$. For each dataset, a daily accumulation/precipitation rate is calculated at each time point (three-hourly for ADG and ERA; sixhourly for NCEP) with the day defined as the $12 \mathrm{~h}$ before and $12 \mathrm{~h}$ after the time point. An event is defined for each dataset as the period of time that the accumulation/precipitation rate

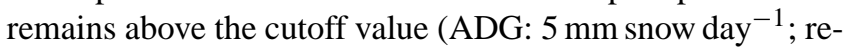
analyses: $0.5 \mathrm{~mm}$ w.e. day ${ }^{-1}$ ), and only events lasting longer than $6 \mathrm{~h}$ are considered. Coincident events are then determined by identifying the reanalyses events which overlap in time with or are within $24 \mathrm{~h}$ of an ADG event. 


\section{Results}

Figure 2 shows each station's ADG accumulation record along with the ERA and NCEP precipitation. Snow accumulation and precipitation events are seen as stepped increases in the plots. Decreases in accumulation seen in the ADG records indicate the effects of ablation, compaction, or sublimation, and are not accounted for in the reanalyses plots, which show only positive changes due to precipitation. Though negative accumulation processes are very important for surface mass balance, they are not considered in this study as we are simply attempting to identify precipitation events. For an approximate comparison of the magnitudes between the datasets (snow accumulation and precipitation), a snow density of $350 \mathrm{~kg} \mathrm{~m}^{-3}$ is used to equate each station's $y$ axes in Fig. 2. The reanalyses precipitation shows that ERA produces much more accumulation than NCEP ( two to four times as much over the varying time periods) with the exception of Ferrell, Margaret, and Nascent, which have similar total precipitation amounts for ERA and NCEP over these time periods.

As precipitation in the reanalyses forecast models is largely driven by the meridional (moisture-bearing) circulation and the amount of water available (Kalnay et al., 1996; Dee et al., 2011), we look at the differences between ERA and NCEP for these parameters in order to understand why the precipitation amounts differ so much. Figure $3 a$ and $b$ show the difference between ERA and NCEP (ERA minus NCEP) total precipitable water and near-surface meridional winds $(850 \mathrm{hPa})$ over the RIS averaged from 2008 to 2012. Interestingly, Figure 3a shows that the ERA reanalysis has less moisture over much of the RIS and Ross Sea, but more along the TAM, which is consistent with the larger amounts of precipitation produced by ERA for stations along the TAM, while the stations further from the TAM (Ferrell, Margaret, and Nascent) produce similar amounts to NCEP. Figure $3 \mathrm{~b}$ shows that ERA has a weaker southerly component (more positive $\mathrm{v}$ wind) for air coming from the Ross Sea (moisture-bearing) onto the RIS, but a stronger southerly component along the TAM. The weaker cyclonic circulation over the RIS in ERA is thus able to explain the differences in total precipitable water. The figures show that the largest differences between ERA and NCEP for both water content and meridional circulation are along the TAM. This is possibly due to the higher spatial resolution of the ERA model being able to more accurately reproduce the effects of the barrier formed by the TAM.

Figure 4 shows a close-up of six days in the ADG, ERA, and NCEP records for Margaret station (corresponding to the grey box in Fig. 2). The figure illustrates the characteristics typical of most of the coincident events identified in all of the stations. The highly stepped nature of ADG accumulation events is clear, as is the more broad nature of reanalyses events. The duration of events are different for each dataset,
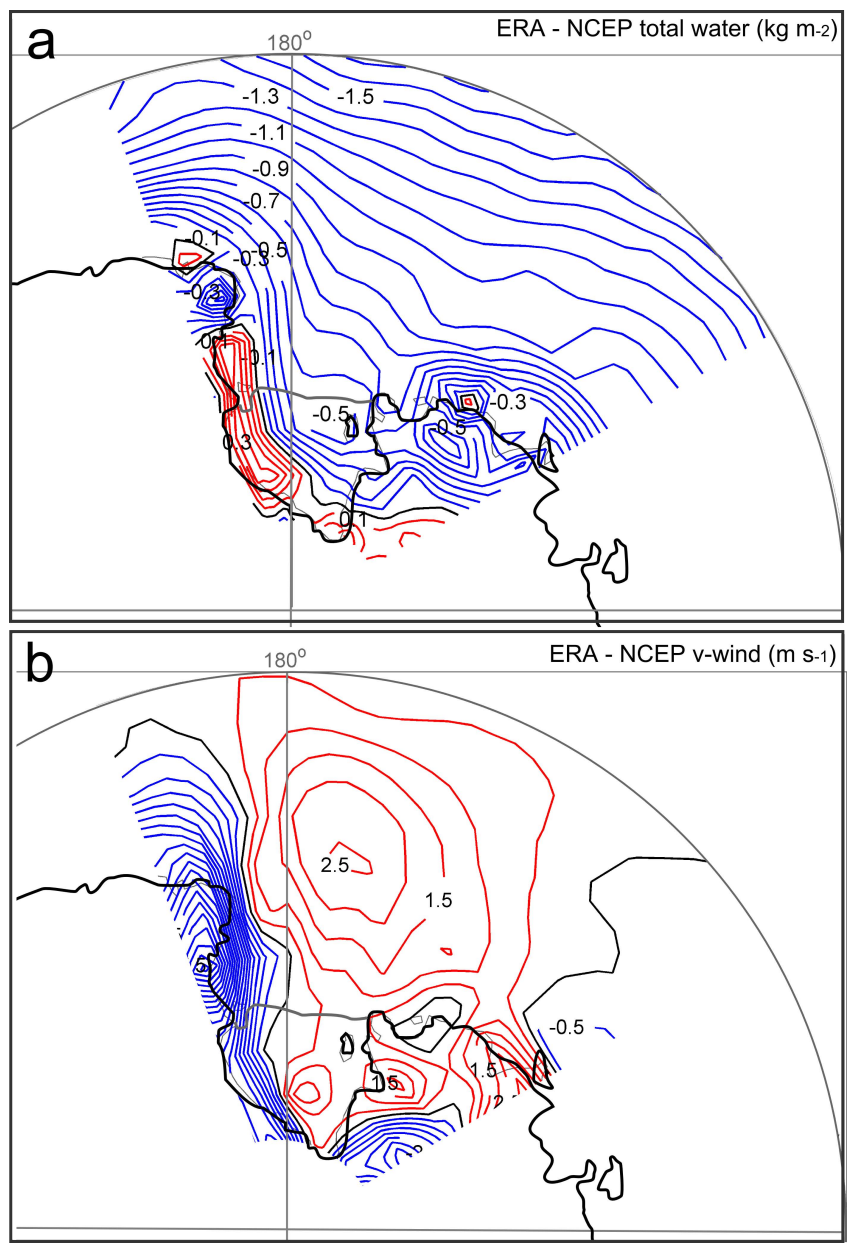

Fig. 3. Differences between ERA and NCEP reanalyses (ERA minus NCEP) from 2008 to 2012 over the Ross Sea and RIS region $\left(60-85^{\circ} \mathrm{S}, 160-240^{\circ} \mathrm{E}\right)$ for (a) total precipitable water (total column water) $\left(\mathrm{kg} \mathrm{m}^{-2}\right)$ and (b) $850 \mathrm{hPa}$ meridional winds $\left(\mathrm{m} \mathrm{s}^{-1}\right)$. Red contours are positive (ERA larger than NCEP), blue contours are negative (NCEP larger than ERA), and grey line is zero. Total precipitable water contours are $0.1 \mathrm{~kg} \mathrm{~m}^{-2}$, and wind contours are $0.5 \mathrm{~m} \mathrm{~s}^{-1}$.

but the events overlap in time (or are within $24 \mathrm{~h}$, as discussed in Sect. 3.3) as illustrated in Fig. 4.

The greater duration of reanalyses events as compared to the ADG events is seen throughout the datasets. The mean duration of coincident events for all ADG events is $27 \mathrm{~h}$, while the mean durations for ERA and NCEP are 65 and $61 \mathrm{~h}$ respectively. While this may indicate that the cutoff value for the reanalyses data is too low, increasing the cutoff value to a much higher value $\left(2 \mathrm{~mm}\right.$ w.e. day $\left.{ }^{-1}\right)$ decreases the average duration of events to 48 and $46 \mathrm{~h}$ for ERA and NCEP respectively, which is still much longer than the ADG events and decreases the number of events by $\sim 60 \%$ for both ERA and NCEP. That the reanalyses-derived events are much longer in duration than the ADG-derived events indicates that this is likely a result of the parameterization of synoptically driven 


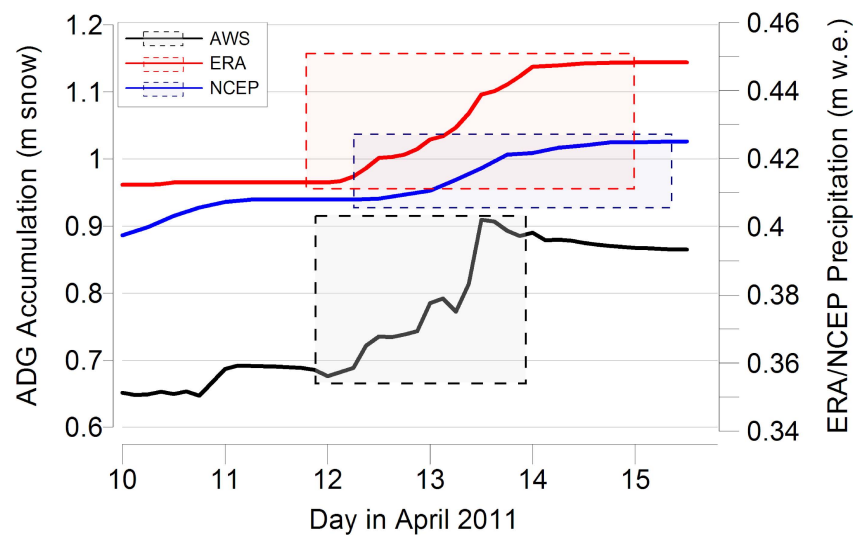

Fig. 4. Zoomed-in section of the Margaret accumulation plot (corresponding to the grey box in Margaret in Fig. 2) showing the characteristics typical of a coincident event. ADG snow accumulation is on the left-hand $y$ axis, and ERA/NCEP precipitation is on the righthand $y$ axis as in Fig. 2 (note axes are different scales for clarity). The dashed boxes indicate the different durations of the coincident event (defined as $>5 \mathrm{~mm} \mathrm{snow} \mathrm{day}^{-1}$ and $>0.5 \mathrm{~mm}^{2}$.e. day ${ }^{-1}$ ) for each dataset.

precipitation in reanalyses forecast models and is worth further investigation.

Table 2 shows the number of accumulation events $\left(>5 \mathrm{~mm} \mathrm{day}^{-1}\right.$ for ADG and $>0.5 \mathrm{~mm} \mathrm{day}^{-1}$ for reanalyses) identified for each of the ADG, ERA, and NCEP datasets as well as the number of coincident events for each pairing (ADG-ERA and ADG-NCEP). The probability that the number of coincident events in each time series is random is determined from the hypergeometric probability density distribution, and is much less than 0.01 for all pairings. For all stations except Nascent, ERA produces a much larger number of precipitation events, and except for Sabrina, a higher percentage of these events are coincident with ADG events.

Table 3 shows the percentage of coincident events captured by reanalyses datasets and the percentage of precipitation derived from these coincident events. ERA events coincide with between 22 and $51 \%$ of ADG events, and NCEP events coincide with between 14 and $40 \%$ of ADG events. On average, ERA captures a higher percentage of ADG events than NCEP (average $37 \%$ versus $23 \%$ ). Because of the known considerable influence of wind-redistributed snow on snow accumulation discussed in Section 2, many of the events identified in the ADG data may actually be due to blowing/drifting snow, where no precipitation occurred, and as such we would not necessarily expect these percentages to be very high. Identifying and quantifying these events is very difficult, and is a persistent challenge in snow accumulation studies. The coincident events do correspond to sizeable amounts of the total reanalysis precipitation (between 63 and $86 \%$ and between 48 and $79 \%$ for ERA and NCEP respectively), with ERA producing an average of $8.2 \%$ (significant at the $93 \%$ confidence level) more precipitation than NCEP.
That ERA captures on average $14 \%$ more events but only $8.2 \%$ more precipitation indicates that the "extra" events ERA is capturing are smaller precipitation events.

Table 3 also shows the percentage of reanalyses events that are not seen in the ADG data ("false" events). The NCEP reanalyses dataset has more false events than ERA (average $50 \%$ and $44 \%$ respectively). These events would include cases where snow accumulation is less than the ADG threshold of $5 \mathrm{~mm} \mathrm{day}^{-1}$ (either due to small amounts of precipitation or wind limiting accumulation) or the event does not fall within the $48 \mathrm{~h}$ window used to define a coincident event. Distinguishing between these circumstances are difficult, but in a study of one ADG record on the RIS, Braaten (1997) found that $38 \%$ of meteorologist-observed precipitation events resulted in no measured accumulation in the ADG record, suggesting that identifying whether the additional reanalyses events are in fact real is beyond the capability of the ADG dataset.

To assess the effect of changing the reanalysis event size cutoff on the analysis, we compare the number of coincident events and percentage of precipitation captured by coincident events using different reanalyses cutoff values of $0.35 \mathrm{~mm} \mathrm{day}^{-1}, 0.5 \mathrm{~mm} \mathrm{day}^{-1}, 1 \mathrm{~mm} \mathrm{day}^{-1}$, and $2 \mathrm{~mm} \mathrm{day}^{-1}$ (the values in Tables 2 and 3 are calculated using $\left.0.5 \mathrm{~mm} \mathrm{day}^{-1}\right)$. The two smallest values $(0.35$ and $0.5 \mathrm{~mm} \mathrm{day}^{-1}$ ) are equivalent to the ADG measurement cutoff value $\left(5 \mathrm{~mm} \mathrm{day}^{-1}\right)$ using freshly precipitated snow densities (7 and $10 \%$ ). Not surprisingly, increasing the reanalyses cutoff decreases the number of coincident events and amount of precipitation accounted for. Over this range of cutoff values the average percentage of coincident events captured for all stations decreases from 40 to $24 \%$ for ERA and from 27 to $13 \%$ for NCEP. The average percentage of precipitation accounted for decreases from 77 to $61 \%$ for ERA and from 70 to $49 \%$ for NCEP. For the NCEP dataset, though the decrease in number of coincident events is similar to ERA (16 vs. $14 \%$ ), a larger change in the amount of precipitation (16 vs. $21 \%$ ) is seen. This suggests that the NCEP dataset produces more precipitation at smaller amounts, making it more sensitive to the lower cutoff values. The percentage of "false" events also changes much more in the NCEP dataset, decreasing from 51 to $39 \%$ as the cutoff increases (from 0.35 to $2 \mathrm{~mm} \mathrm{day}^{-1}$ ), while ERA "false" events change only slightly from 44 to $40 \%$.

For further comparison of the coincident events identified between ADG and reanalyses data, Fig. 5 plots the sizes of coincident events for each station to show the relationships between the ADG and reanalyses events. The sizes are calculated as the total amount of precipitation/accumulation during each coincident event. Although we cannot directly compare the sizes (snow versus water equivalent), a range of snow densities for freshly fallen snow (70 to $120 \mathrm{~kg} \mathrm{~m}^{-3}$ ) and wind-redistributed snow $\left(250 \mathrm{~kg} \mathrm{~m}^{-3}\right)$ is shown as dashed lines in Fig. 5. Least-squares linear regressions and correlations ( $r$ values) are shown for the relationships between ADG 
Table 2. The number of events for ADG, ERA-Interim, and NCEP-2 datasets and number of coincident events.

\begin{tabular}{lccc|ccc}
\hline & \multicolumn{5}{c}{ Number of Events } \\
& ADG $^{\mathrm{a}}$ & ERA & ADG-ERA & ADG $^{\mathrm{b}}$ & NCEP & ADG-NCEP \\
\hline Byrd & 51 & 50 & 26 & 42 & 22 & 11 \\
Sabrina & 182 & 173 & 73 & 170 & 127 & 68 \\
Elaine & 146 & 98 & 59 & 137 & 84 & 37 \\
Margaret & 237 & 143 & 72 & 235 & 118 & 58 \\
Nascent & 200 & 65 & 44 & 200 & 80 & 40 \\
Mary & 305 & 154 & 97 & 305 & 82 & 42 \\
Linda & 59 & 42 & 27 & 49 & 16 & 8 \\
Ferrell & 94 & 81 & 33 & 94 & 55 & 23 \\
Windless Bight & 369 & 209 & 142 & 353 & 112 & 66 \\
\hline a to 31 Aug 2012 & \multicolumn{7}{|l}{}
\end{tabular}

Table 3. Percentages of ADG events captured by reanalysis datasets, the amount of precipitation captured by those events (as a percentage of the total reanalysis precipitation), and percentage of reanalysis events that are not seen in ADG data ("false" events) for each reanalysis dataset.

\begin{tabular}{lccc|ccc}
\hline & \multicolumn{3}{c|}{ ERA } & \multicolumn{3}{c}{ NCEP } \\
\cline { 2 - 7 } & $\begin{array}{c}\text { ADG } \\
\text { captured } \\
(\%)\end{array}$ & $\begin{array}{c}\text { Precipitation } \\
(\%)\end{array}$ & $\begin{array}{c}\text { "False" } \\
\text { events } \\
(\%)\end{array}$ & $\begin{array}{c}\text { ADG } \\
\text { captured } \\
(\%)\end{array}$ & $\begin{array}{c}\text { Precipitation } \\
(\%)\end{array}$ & $\begin{array}{c}\text { "False" } \\
\text { events } \\
(\%)\end{array}$ \\
\hline Byrd & 51.0 & 70.8 & 48.0 & 26.2 & 67.7 & 50.0 \\
Sabrina & 40.1 & 63.0 & 57.8 & 40.0 & 74.5 & 46.5 \\
Elaine & 40.4 & 81.5 & 39.8 & 27.0 & 72.0 & 56.0 \\
Margaret & 30.4 & 67.3 & 49.7 & 24.7 & 59.7 & 50.8 \\
Nascent & 22.0 & 81.9 & 32.3 & 20.0 & 74.6 & 50.0 \\
Mary & 31.8 & 78.4 & 37.0 & 13.8 & 62.4 & 48.8 \\
Linda & 45.8 & 71.0 & 35.7 & 16.3 & 47.7 & 50.0 \\
Ferrell & 35.1 & 71.6 & 59.3 & 24.5 & 59.9 & 58.2 \\
Windless Bight & 38.5 & 85.8 & 32.1 & 18.7 & 79.0 & 41.1 \\
\hline
\end{tabular}

and reanalyses event sizes that are significant at $90 \%$ level. Regression lines which lie near the range of fresh snow densities with zero-intercept and higher correlation coefficients indicate better relationships between reanalyses precipitation and ADG data.

Five of the nine stations have significant relationships with both ERA and NCEP (Elaine, Margaret, Mary, Ferrell, and Windless Bight), and one has a significant relationship with NCEP (Byrd), indicating that many precipitation events are being accurately represented by both reanalyses datasets. The $r$ values vary between 0.26 and 0.69 , with neither reanalyses product showing higher correlations over all stations. The regressions show that ERA events are generally larger than NCEP events. The smaller values seen in NCEP would be consistent with previous studies showing that NCEP underestimates precipitation in Antarctica (Cullather et al., 1996; Zou et al., 2004). However the NCEP regressions are not consistent enough to draw any conclusions about biases, and none are significantly lower than expected values. The one regression that is significantly higher than expected values (Ferrell) is dominated by several events.

The complex effects of wind on ADG snow accumulation means that we cannot determine biases in reanalyses precipitation amounts. In Fig. 5, events that are in the region above the freshly fallen snow densities could have several causes: snow accumulation being limited by wind, higher snow densities due to wind-blown snow, or reanalysis overestimating event sizes; events that fall below the range could be either due to excess accumulation due to wind or reanalysis underestimating event sizes. At sites known to exhibit significant ablation such as Ferrell, Mary, Nascent, and Sabrina (Braaten, 1997; Knuth et al., 2010; Nigro et al., 2011), where we would expect a low bias in the ADG data (i.e. ADG snow accumulation is often limited due to wind), these sites do show a significant number of events where reanalyses are much larger than ADG events (except for the NCEP events with Mary). At Windless Bight, which is a low-wind, highaccumulation site (Knuth et al., 2010) where we would expect a high bias in the ADG (i.e. ADG snow accumulation is 

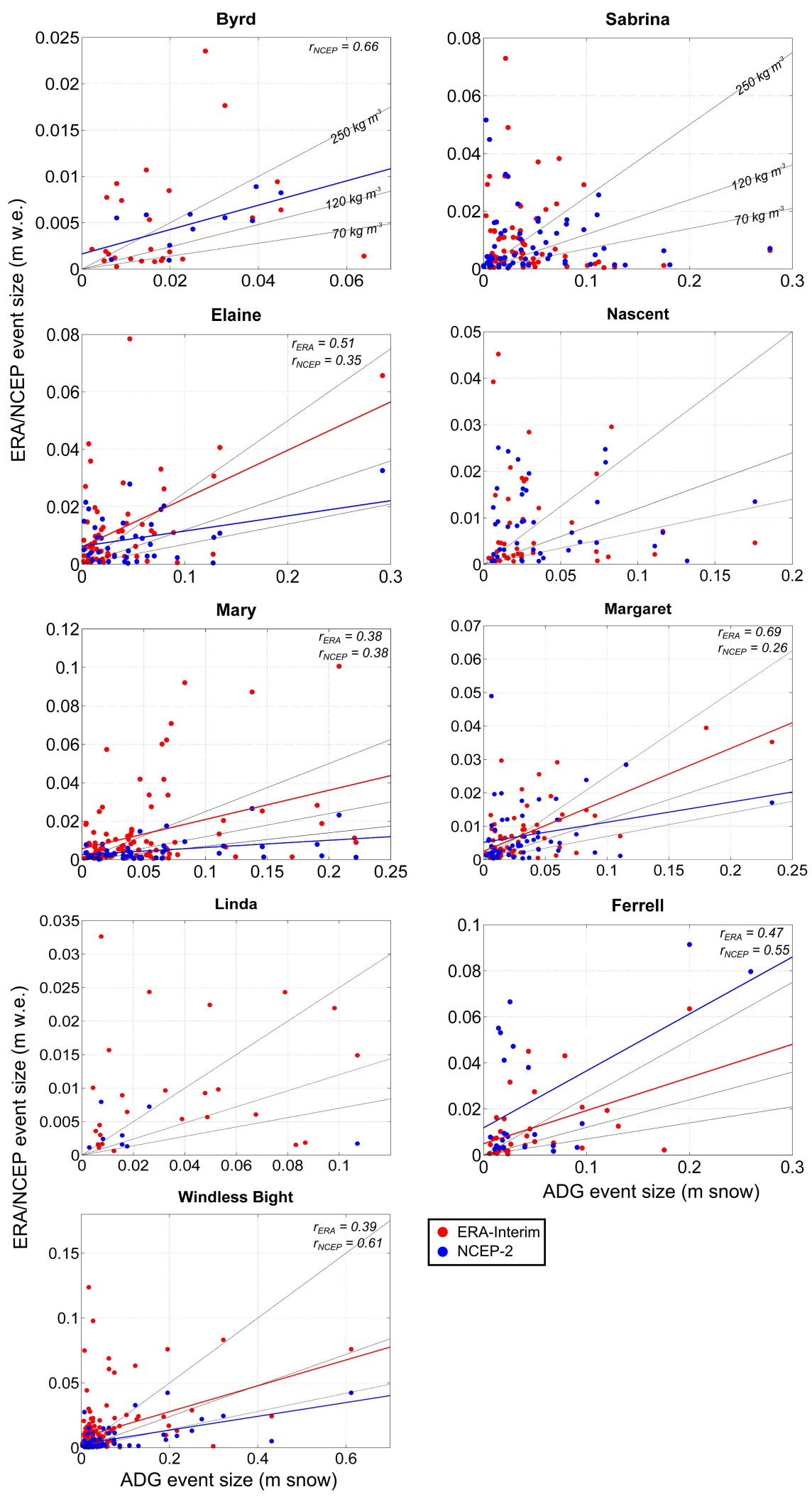

ERA-Interim

- NCEP-2

Fig. 5. Comparison of event sizes for all coincident events. ADG event sizes are $m$ snow; reanalyses event sizes are $m$ w.e. Regression lines and $r$ values are shown for correlations at $90 \%$ significance level. Black lines indicate the slope of the regression that would be expected for snow densities at various ranges (freshly fallen snow, $\rho=70-120 \mathrm{~kg} \mathrm{~m}^{-3}$; wind-redistributed snow, $\rho=250 \mathrm{~kg} \mathrm{~m}^{-3}$ ) 


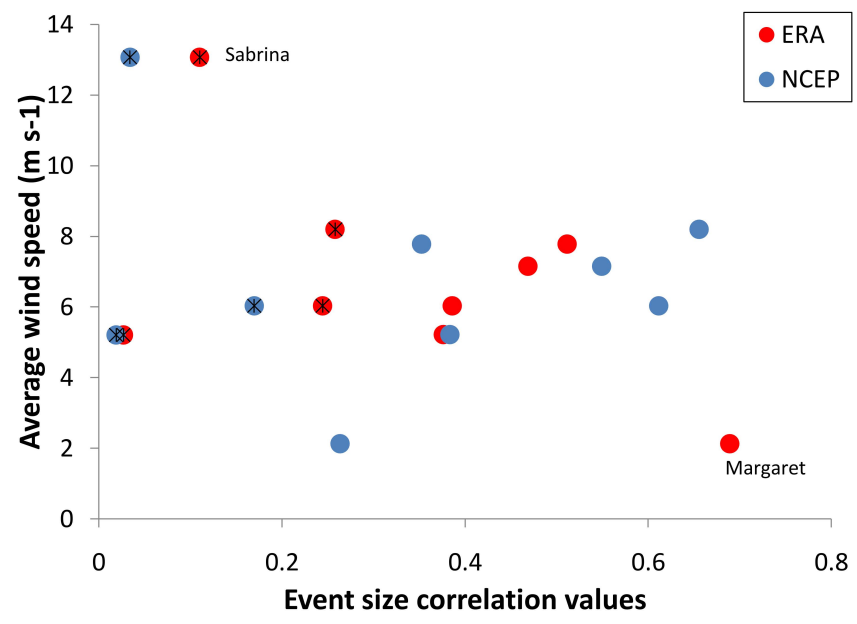

Fig. 6. Relationship between near-surface wind speed and event size correlation values (from Fig. 5), including those not significant at $>90 \%$ level (indicated with asterisk). Wind speed values are derived from ERA-Interim $850 \mathrm{hPa}$ monthly averages $(750 \mathrm{hPa}$ for Byrd), averaged over the period of this study (2008-2012). Stations with the highest (Sabrina) and lowest (Margaret) wind speed are labelled.

often enhanced by wind conditions), the ERA and NCEP regressions do reflect this (via regression slopes closer to freshsnow values). However, the ERA data for this site still show a significant number of events where ERA events are much larger than ADG events. Finally, Margaret, which is located in the least wind-affected region of the RIS (Parish et al., 2006), has the highest correlation and near-zero intercept for the ERA data, but interestingly has the lowest correlation for NCEP. Figure 6 illustrates the relationship between average near-surface wind speed from 2008 to 2012 and the eventsize correlation values from Fig. 5 (including those that are not significant). The figure supports the notion that the sites located in windier locations tend have the lowest correlations between ADG-measured events and reanalysis events.

\section{Conclusions}

This study develops an event-based analysis of ADG snow accumulation records from nine AWS located around the Ross Ice Shelf, and compares the observations to precipitation from ERA-Interim and NCEP-2 reanalyses. This provides an assessment of the feasibility to use these measurements as validation for precipitation in reanalyses and other NWP models. The high-temporal-resolution ADG measurements provide a relatively dense network of multi-year accumulation records in a relatively homogeneous region of Antarctica, and are shown to provide some insight into reanalyses precipitation on synoptic timescales for recent time periods (2008-2012). Analysis of the number of events in each dataset shows that, for all locations, ERA has more matching events with the ADG measurements than NCEP, capturing an average $37 \%$ of ADG accumulation events versus $23 \%$ for NCEP. These coincident events correspond to an average 75 and $66 \%$ of the total reanalyses precipitation for ERA and NCEP respectively. Quantifying how many of the ADG events are precipitation versus blowing/drifting snow (and thus how many events the reanalyses are missing) is a difficult and ongoing challenge in measuring precipitation. Previous estimates of the number of wind-affected accumulation events from ADG data (which may or may not be coincident with precipitation events) on the RIS are of the order of $70 \%$ (Knuth et al., 2010), suggesting that the reanalyses may actually be capturing most precipitation events. Overall this analysis suggests that the ERA data perform better than NCEP, capturing $14 \%$ more events and $8.2 \%$ more precipitation.

Comparisons of the sizes of coincident events between ADG and reanalyses data show that there are significant correlations (at $>90 \%$ ) for several of the stations, and these correlations are near the range of expected values, providing further evidence that the reanalyses are reproducing actual precipitation events. The ERA data consistently produce more precipitation per event than the NCEP data, which is consistent with capturing more precipitation overall. Neither reanalyses dataset shows consistently higher correlations with the ADG event sizes, but using known biases of windlimiting snow (Ferrell, Nascent, Mary, Sabrina) or windenhancing snow (Windless Bight) helps interpret some of the overall patterns of the event size correlations. ERA consistently shows correlations in the upper range of expected snow densities, while NCEP less consistently shows correlations in the lower range of expected snow densities.

Determination of the biases in the reanalyses datasets (i.e. ERA overestimating or NCEP underestimating precipitation) is not possible due to the limitation of the ADG dataset. Further work to identify biases and make quantitative estimates would require extensive further analysis of sitespecific wind conditions and snow density. In terms of providing snow accumulation measurements, the placement of most of the ADGs on the Ross Ice Shelf is not ideal since they are specifically located in katabatic and barrier wind regimes where snow accumulation is highly affected by winds. Despite this, the analysis shows important differences between the two datasets, and indicates that the ADG measurements could be used more extensively in the future to provide a valuable source of ground-based precipitation observations.

Acknowledgements. The authors appreciate the support of the University of Wisconsin-Madison Automatic Weather Station Program for the acoustic depth gauge AWS dataset, NSF grant number ANT-0944018. We also appreciate use of the NCEP Reanalysis-2 data provided by the NOAA/OAR/ESRL PSD, Boulder, Colorado, and the use of ERA-Interim data provided by the European Centre for Medium-Range Forecasts. S. Dean's contribution to this manuscript was funded by NIWA under the 
"Climate Present and Past" project of the National Climate Centre's Climate Observations Programme (2012/13 SCI).

Edited by: M. Van den Broeke

\section{References}

Andersson, E., Holm, E., Bauer, P., Bejaars, A., Kelly, G. A., McNally, A. P., Simmons, A. J., Thepaut, J. N., and Tompkins, A. M.: Analysis and forecast impact of the main humidity observing systems, Q. J. Roy. Meteor. Soc., 133, 1473-1485, 2007.

Arthern, R. J., Vaughan, D. G., Rankin, A. M., Mulvaney, R., and Thomas, E. R.: In situ measurements of Antarctic snow compaction compared with predictions of models, J. Geophys. Res., 115, F03011, doi:10.1029/2009JF001306, 2010.

Braaten, D.: A detailed assessment of snow accumulation in katabatic wind areas on the Ross Ice Shelf, Antarctica, J. Geophys. Res., 102, 30047-30058, 1997.

Braaten, D.: Direct measurements of episodic snow accumulation on the Antarctic polar plateau, J. Geophys. Res., 105, 1011910128, 2000.

Brazenec, W. A. and Doesken, N. J.: An evaluation of two ultrasonic snow depth sensors for potential use at automated surface weather observing sites, 13th Symposium on Meteorological Observations and Instrumentation, American Meteorological Society, Savannah, GA, 2005.

Bromwich, D. H.: Snowfall in high southern latitudes, Rev. Geophys., 26, 149-168, 1988.

Bromwich, D. H., Guo, Z., Bai, L., and Chen, Q.: Modeled Antarctic Precipitation - Part I: Spatial and Temporal Variability, J. Climate, 17, 427-447, 2004.

Bromwich, D. H., Fogt, R. L., Hodges, K. I., and Walsh, J. E.: A tropospheric assessment of the ERA-40, NCEP, and JRA-25 global reanalyses in the polar regions, J. Geophys. Res., 112, D10111, doi:10.1029/2006JD007859, 2007.

Bromwich, D. H., Nicolas, J. P., and Monaghan, A. J.: An assessment of precipitation changes over Antarctica and the Southern Ocean since 1989 in contemporary global reanalyses, J. Climate, 24, 4189-4209, 2011.

Bromwich, D. H., Nicolas, J. P., Monaghan, A. J., Lazzara, M. A., Keller, L. M., Weidner, G. A., Wilson, A. B.: Central West Antarctica among the most rapidly warming regions on Earth, Nat. Geosci., 6, 139-145, doi:10.1038/ngeo1671, 2012.

Cohen, L., Dean, S., and Renwick, J.: Synoptic Weather Types for the Ross Sea Region, Antarctica, J. Climate, 26, 636-649, doi:10.1175/JCLI-D-11-00690.1, 2013.

Cullather, R. I., Bromwich, D. H., and Van Woert, M. L.: Interannual variations in Antarctic precipitation related to El NiñoSouthern Oscillation, J. Geophys. Res., 101, 19109-19118, 1996.

Cullather, R. I., Bromwich, D. H., and van Woert, M. L.: Spatial and temporal variability of Antarctic precipitation from atmospheric methods. J. Climate, 11, 334-367, 1998.

Dee, D. P., Uppala, S. M., Simmons, A. J., Berrisford, P., Poli, P., Kobayashi, S., Andrae, U., Balmaseda, M. A., Balsamo, G., Bauer, P., Bechtold, P., Beljaars, A. C. M., van de Berg, L., Bidlot, J., Bormann, N., Delsol, C., Dragani, R., Fuentes, M., Geer, A. J., Haimberger, L., Healy, S. B., Hersbach, H., Hólm, E. V., Isaksen, L., Kållberg, P., Köhler, M., Matricardi, M., McNally,
A. P., Monge-Sanz, B. M., Morcrette, J.-J., Park, B.-K., Peubey, C., de Rosnay, P., Tavolato, C., Thépaut, J.-N., and Vitart, F.: The ERA-Interim reanalysis: configuration and performance of the data assimilation system. Q. J. Roy. Meteor. Soc., 137, 553-597, doi:10.1002/qj.828, 2011.

Eisen, O., Frezzotti, M., Genthon, C., Isaksson, E., Magand, O., Van den Broeke, M. R., Dixon, D. A., Ekaykin, A., Holmlund, P., Kameda, T., Karlo, L., Kaspari, S., Lipenkov, V. Y., Oerter, H., Takahashi, S., and Vaughan, D. G.: Ground-based measurements of spatial and temporal variability of snow accumulation in East Antarctica, Rev. Geophys., 46, RG2001, doi:10.1029/2006RG000218, 2008.

Fogt, R. L. and Bromwich, D. H.: Decadal Variability of the ENSO Teleconnection to the High-Latitude South Pacific Governed by Coupling with the Southern Annular Mode, J. Climate, 19, 979997, 2006.

Fogt, R. L., Wovrosh, A. J., Langen, R. A., and Simmonds, I.: The characteristic variability and connection to the underlying synoptic activity of the Amundsen-Bellingshausen Seas Low, J. Geophys. Res., 117, D07111, doi:10.1029/2011JD017337, 2012.

Fountain, A. G., Nylen, T. H., Monaghan, A., Basaigic, H. J., and Bromwich, D.: Snow in the McMurdo Dry Valleys, Antarctica, Int. J. Climatol., 30, 633-642, doi:10.1002/joc.1933, 2010.

Helsen, M. M., van de Wal, R. S. W., and Van den Broeke, M. R.: The isotopic composition of present-day Antarctic snow in a Lagrangian atmospheric simulation, J. Climate, 20, 739-756, 2007.

Kalnay, E., Kanamitsu, M., Kistler, R., Collins, W., Deaven, D., Gandin, L., Iredell, M., Saha, S., White, G., Woollen, J., Zhu, Y., Leetmaa, A., Reynolds, R., Chelliah, M., Ebisuzaki, W., Higgins, W., Janowiak, J., Mo, K. C., Ropelewski, C., Wang, J., Jenne, R., and Joseph, D.: The NCEP/NCAR 40-Year Reanalysis Project, B. Am. Meteorol. Soc., 77, 437-470, 1996.

King, J. C. and Turner, J.: Antarctic Meteorology and Climatology, Cambridge University Press, 409 pp., 1997.

Knuth, S. L., Tripoli, G. J., Thom, J. E., and Weidner, G. A.: The influence of blowing snow and precipitation on snow depth change across the Ross Ice Shelf and Ross Sea regions of Antarctica, J. Appl. Meteor. Climatol., 49, 1306-1321, 2010.

Kojima, K.: Densification of snow in Antarctica, in Antarctic Snow and Ice Studies, in: Antarct. Res. Ser., vol. 2, edited by: Mellor, M., 157-218, AGU, Washington, DC, doi:10.1029/AR002p0157, 1964.

Krinner, G., Magand, O., Simmonds, I., Genthon, C., and Dufresne, J. L.: Simulated Antarctic precipitation and surface mass balance at the end of the twentieth and twenty-first centuries, Clim. Dynam., 28, 215-230, 2007.

Lazzara, M. A., Weidner, G. A., Keller, L. M., Thom, J. E., and Cassano, J. J.: Antarctic Automatic Weather Station Program: 30 years of polar observations, B. Am. Meterol. Soc., 93, 15191537, 2012.

Li, L. and Pomeroy, J. W.: Probability of occurrence of blowing snow, J. Geophys. Res., 102, 21955-21964, 1997.

Lu, C., Yuan, H., Tollerud, E. I., and Wang, N.: Scale-dependent uncertainties in global QPFs and QPEs from NWP model and satellite fields. J. Hydrometerol., 11, 139-155, 2010.

Marshall, G. J.: On the annual and semi-annual cycles of precipitation across Antarctica, Int. J. Climatol., 29, 2298-2308, doi:10.1002/joc.1810, 2009. 
Monaghan, A. J., Bromwich, D. H., Powers, J. G., and Manning, K. W.: The climate of the McMurdo, Antarctica, region as represented by one year of forecasts from the Antarctic Mesoscale Prediction System, J. Climate, 18, 1174-1189, 2005.

Monaghan, A. J., Bromwich, D. H., Fogt, R. L., Wang, S.H., Mayewski, P. A., Dixon, D.A., Ekaykin, A., Frezzotti, M., Goodwin, I., Isaksson, E., Kaspari, S. D., Morgan, V. I., Oerter, H., van Ommen, T. D., van der Veen, C. J., Wen, J.: Insignificant change in Antarctic snowfall since the International Geophysical Year, Science, 313, 827-831, 2006.

Nigro, M. A., Cassano, J. J., and Seefeldt, M. W.: A weather-pattern based approach to evaluate Antarctic Mesoscale Prediction System (AMPS) forecasts: Comparison to automatic weather station observations, Weather Forecast., 26, 184-198, 2011.

Noone, D. and Simmonds, I.: Annular variations in moisture transport mechanisms and the abundance of $\mathrm{d} 18 \mathrm{O}$ in Antarctic snow, J. Geophys. Res., 107, 4742, doi:10.1029/2002JD002262, 2002.

Parish, T. R., Cassano, J. J., and Seefeldt, M. W.: Characteristics of the Ross Ice Shelf air stream as depicted in Antarctic Mesoscale Prediction System simulations, J. Geophys. Res., 111, D12109, doi:10.1029/2005JD006185, 2006.

Pomeroy, J. and Brun, E.: Physical Properties of Snow in: Snow Ecology: An Interdisciplinary Examination of Snow-Covered Ecosystems, Cambridge University Press, 45-126, 2001.

Qin, D., Xiao, C., Allison, I., Bian L., Stephenson, R., Ren, J., and Yan, M.: Snow surface height variations on the Antarctic ice sheet in Princess Elizabeth Land, Antarctica: 1 year data from an automatic weather station, Ann. Glaciol., 39, 181-187, 2004.

Reijmer, C. H. and Van den Broeke, M. R.: Temporal and spatial variability of the surface mass balance in Dronning Maud Land, Antarctica, as derived from automatic weather stations, J. Glaciol., 49, 512-520, doi:10.3189/172756503781830494, 2003.
Reijmer, H., Van den Broeke, M. R., and Scheele, M. P.: Air parcel trajectories and snowfall related to five deep drilling locations in Antarctica based on the ERA-15 dataset, J. Climate, 15, 19571968, 2002.

Simmons, A. J., Willett, K. M., Jones, P. D., Thorne, P. W., and Dee, P. D.: Low-frequency variations in surface atmospheric humidity, temperature, and precipitation: Inferences from reanalyses and monthly gridded observational data sets, J. Geophys. Res., 115, D01110, doi:10.1029/2009JD012442, 2010.

Simmonds, I., Keay, K., and Lim, E. P.: Synoptic activity in the seas around Antarctica, Mon. Weather Rev., 131, 272-288, 2003.

Sinclair, K. E., Bertler, N. A. N., and Trompetter, W. J.: Synoptic controls on precipitation pathways and snow delivery to highaccumulation ice core sites in the Ross Sea region, Antarctica. J. Geophys. Res., 115, D22112, doi:10.1029/2010JD014383, 2010.

Thiery, W., Gorodetskaya, I. V., Bintanja, R., Van Lipzig, N. P. M., Van den Broeke, M. R., Reijmer, C. H., and Kuipers Munneke, P.: Surface and snowdrift sublimation at Princess Elisabeth station, East Antarctica, The Cryosphere, 6, 841-857, doi:10.5194/tc-6841-2012, 2012.

Thomas, E. R. and Bracegirdle, T. J.: Improving ice core interpretation using in situ and reanalysis data, J. Geophys. Res., 114, D20116, doi:10.1029/2009JD012263, 2009.

Zou, C. Z., van Woert, M. L., Xu, C. Y., and Syed, K.: Assessment of the NCEP-DOE Reanalysis-2 and TOVS Pathfinder A moisture fields and their use in Antarctic net precipitation estimates, Mon. Weather Rev., 132, 2463-2476, 2004. 